\title{
Phosphoramidite-Cu(OTf) Complexes as Chiral Catalysts for 1,3-Dipolar Cycloaddition of Iminoesters and Nitroalkenes
}

\author{
Luis M. Castelló, ${ }^{a}$ Carmen Nájera, ${ }^{a}$ José M. Sansano ${ }^{*}{ }^{a}$ Olatz \\ Larrañaga, ${ }^{b}$ Abel de Cózar ${ }^{b, c}$ and Fernando P. Cossío \\ ${ }^{a}$ Departamento de Química Orgánica e Instituto de Síntesis Orgánica (ISO). Facultad de \\ Ciencias, Universidad de Alicante, 03080-Alicante,Spain. \\ ${ }^{b}$ Departmento de Química Orgánica I, Facultad de Química, Universidad del País Vasco \\ P. K. 1072, E-20018 San Sebastián, Spain. \\ ${ }^{c} I K E R B A S Q U E$, Basque Foundation for Science, 48011 Bilbao, Spain.
}

jmsansano@ua.es

Received Date (will be automatically inserted after manuscript is accepted)
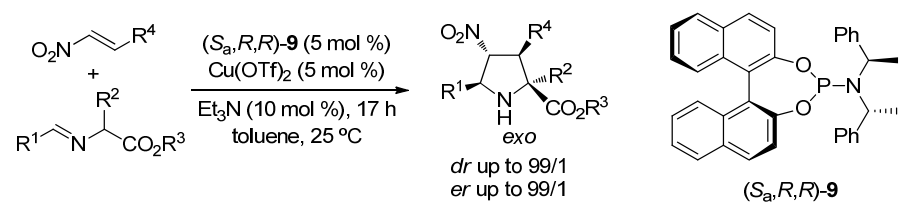

Chiral complexes formed by phosphoramidites such as $\left(S_{a}, R, R\right)-9$ and $\mathrm{Cu}(\mathrm{OTf})_{2}$ are excellent catalysts for the general 1,3-dipolar cycloaddition between azomethine ylides and nitroalkenes affording the corresponding tetrasubstituted proline esters mainly as exo-cycloadducts in high er at room temperature. The exo-cycloadducts can be obtained in enantiomerically pure form just after simple recrystallization. DFT calculations support the stereochemical results.

Substituted prolinates $\mathbf{1}$, obtained from the corresponding 1,3-dipolar cycloadditions $(1,3-\mathrm{DC})^{1}$ between glycine ester aldimines and nitroalkenes, are important inhibitors of $\alpha_{4} \beta_{1}$-integrin-mediated hepatic melanoma metastasis. ${ }^{2}$ The most simple prolines exo-2 have been recently used as chiral organocatalysts in aldol reactions. ${ }^{3}$ In particular, for the

(1) For recent reviews of asymmetric 1,3-DC, see: (a) Pellissier, H. Tetrahedron 2007, 63, 3235. (b) Nájera, C.; Sansano J. M. in Topics in Heterocyclic Chemistry, A. Hassner, Ed. Springer-Verlag: BerlinHeidelberg, 2008, vol. 12, pp. 117. (c) Stanley, L. M.; Sibi, M. P. Chem. Rev. 2008, 108, 2887. (d) Álvarez-Corral, M.; Muñoz-Dorado, M.; Rodríguez-García, I. Chem. Rev. 2008, 108, 3174. (e) Naodovic, M.; Yamamoto, H. Chem. Rev. 2008, 108, 3132. (f) Nájera, C.; Sansano, J. M.; Yus, M. J. Braz. Chem. Soc. 2010, 21, 377. (g) Kissane, M.; Maguire, A. R. Chem. Soc. Rev. 2010, 39, 845. (h) Adrio, J.; Carretero, J. C. Chem. Commun. 2011, 47, 678

(2) Zubia, A.; Mendoza, L.; Vivanco, S.; Aldaba, E.; Carrascal, T.; Lecea, B.; Arrieta, A.; Zimmerman, T.; Vidal-Vanaclocha, F., Cossío, F. P. Angew. Chem. Int. Ed. 2005, 44, 2903.

(3) Conde, E.; Bello, D.; de Cózar, A.; Sánchez, M.; Vázquez, M. A.; Cossío, F. P. Chem. Sci. 2012, 3, 1486. asymmetric 1,3-DC of nitroalkenes as dipolarophiles chiral copper(I) complexes, formed from ferrocenyl-type phosphanes, have been mainly used as catalysts. ${ }^{3,4}$ Copper(I) complexes $\mathbf{3},{ }^{4 \mathrm{a}, \mathrm{c}} \mathbf{4},{ }^{4 \mathrm{~b}, \mathrm{e}}$ and $\mathbf{5},^{3}$ generally afforded exo ${ }^{5}$-cycloadducts, whereas the corresponding endodiastereomers have been prepared using complex $\mathbf{6}^{3}$ However, when copper(II) triflate and chiral ligand PyBidine $^{6}$ were combined the resulting catalyst 7 afforded

(4) (a) Cabrera, S.; Gómez-Arrayás, R.; Carretero, J. C. J. Am. Chem. Soc. 2005, 127, 16394. (b) Yan, X.-X.; Peng, Q.; Zhang, K.; Hong, W.; Hou, X.-L.; Wu, Y.-D. Angew. Chem. Int. Ed. 2006, 45, 1979. (c) Cabrera, S.; Gómez-Arrayás, R.; Martín-Matute, B.; Cossío, F. P.; Carretero, J. C. Tetrahedron 2007, 63, 6587. (d) Padilla, S.; Tejero, R.; Adrio, J.; Carretero, J. C. Org. Lett. 2010, 12, 5608. (e) Kim, H.-Y.; Li, J.-Y.; Kim, S.; Oh, K. J. Am. Chem. Soc. 2011, 133, 20750. (f) Li, Q.; Ding, C.-H.; Li, X.-H.; Weissensteiner, W.; Hou, X.-L. Synthesis 2012, 44, 265.

(5) The endo/exo descriptor refers the approach of the electronwithdrawing group to the metallodipole before the cycloaddition.

(6) Arai, T.; Mishiro, A.; Yokoyama, N.; Suzuki, K.; Sato, H. J. Am. Chem. Soc. 2010, 132, 5338. 
mainly endo-cycloadducts. In the case of 1,3-DC of glycinamides and nitrostyrene $(R)$-Segphos and $\mathrm{Cu}\left(\mathrm{CH}_{3} \mathrm{CN}\right)_{4} \mathrm{PF}_{6}$ as catalytic mixture, furnished exocycloadducts in good yields (up to $76 \%$ ) and up to $96: 4 \mathrm{er}^{7}$ A 5-position epimer (called exo'-diastereoisomer) was mainly obtained when a solid-phase imidazolidineaminophenol/ $\mathrm{Ni}(\mathrm{OAc})_{2}$ was employed. ${ }^{8}$ Other chiral metal complexes such as [BinapAuTFA $]_{2}$ afforded modest results for the cycloaddition of methyl benzylideneaminoglycinate and nitrostyrene (up to 80:20 dr and 85:15 er). ${ }^{9}$ On the other hand, benzophenone-derived $N$-(diphenylmethylene) glycinates have also been employed as azomethine ylide precursors in the presence of chiral silver catalysts, ${ }^{10}$ and organocatalysts. ${ }^{11}$ In general, only glycinate derived imino esters have been employed as azomethine ylide precursors except in the case of the ligand 7-Cu(OTf $)_{2}$ which catalyzed the 1,3-DC with the corresponding alaninate. In many of these examples the elucidation of the reaction pathways has been studied by both DFT calculations ${ }^{12}$ and experimentally. ${ }^{4 \mathrm{e}}$
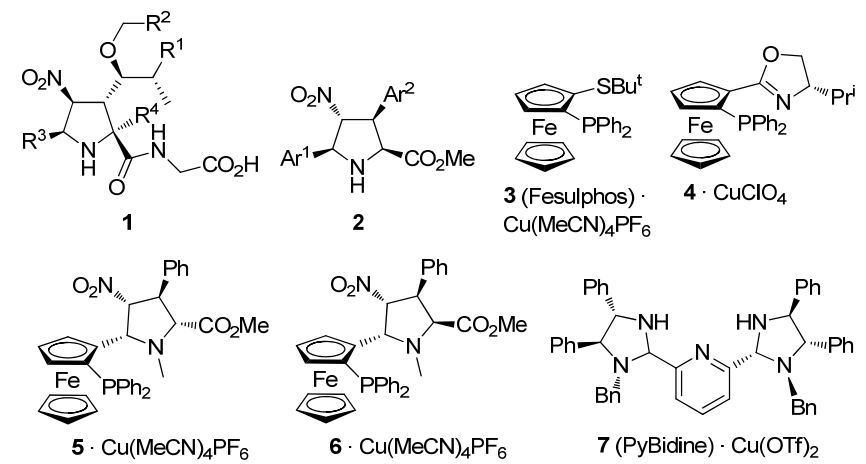

Figure 1. Useful nitro-substituted prolines 1 and 2, and previously reported chiral catalysts for the enantioselective 1,3-DC of imino esters and nitroalkenes.

We envisaged that the use of chiral phosphoramidites 8 and $9,{ }^{13}$ as monodentate privileged ligands, ${ }^{14}$ could be a good alternative to the described sophisticated ligands for

(7) González-Esguevillas, M.; Adrio, J.; Carretero, J. C. Chem. Commun. 2012, 48, 2149.

(8) Arai, T.; Yokoyama, N.; Mishiro, A.; Sato, H. Angew. Chem. Int. Ed. 2010, 49, 7895 .

(9) Martín-Rodríguez, M.; Nájera, C.; Sansano, J. M.; de Cózar, A.; Cossío, F. P. Chem. Eur. J. 2011, 17, 14224.

(10) Imae, K.; Konno, T.; Ogata, K.; Fukuzawa, S.-I. Org. Lett. 2012, 14,4410 .

(11) (a) Xie, J.; Yoshida, K.; Takasu, K.; Takemoto, Y. Tetrahedron Lett. 2008, 49, 6910. (b) Xue, M.-X.; Zhang, X.-M. Gong, L.-Z. Synlett 2008, 691 .

(12) For a review, see: de Cózar, A.; Cossío, F. P. Phys. Chem. Chem. 2011, 13, 10858 .

(13) (a) Teichert, J. F.; Feringa, B. L. Angew. Chem. Int. Ed. 2010, 49, 2486. (b) Privileged Chiral Ligands and Catalysts; Qi-Lin Zhou, Ed.; Wiley-VCH: New York, 2011.

(14) The versatility and efficiency of chiral phosphoramidite $9-\mathrm{AgClO}_{4}$ complex was described firstly by our group: (a) Nájera, C.; Retamosa, M. G.; Sansano, J. M. Angew. Chem. Int. Ed. 2008, 47, 6055. (b) Nájera, C.; Retamosa, M. G.; Martín-Rodríguez, M.; Sansano, J. M.; de Cózar, A.; Cossío, F. P. Eur. J. Org. Chem. 2009, 5622. copper salts ${ }^{15}$ to be used as chiral catalysts in the general asymmetric 1,3-DC of azomethine ylides, derived from $\alpha$ amino acids, and nitroalkenes.
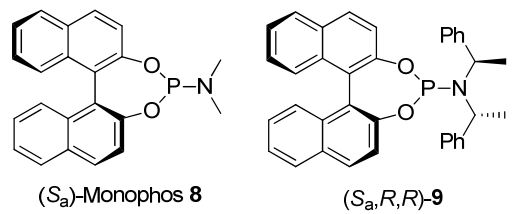

$\left(S_{\mathrm{a}}, R, R\right)-9$

Figure 2. Employed chiral phosphoramidites

Initially, we selected $\left(S_{\mathrm{a}}\right)$-Monophos $\mathbf{8}$ and $\left(S_{a}, R, R\right)-\mathbf{9}$ as chiral phosphoramidites for the preliminary catalyzed $1,3-$ DC between methyl $N$-benzylideneglycinate 10a and $\beta$ nitrostyrene 11a, in toluene as solvent, at room temperature for $17 \mathrm{~h}\left(25^{\circ} \mathrm{C} \text {, Table 1). When }\left(S_{a}\right) \text {-Monophos 8-Cu(OTf }\right)_{2}$ was used as catalyst mainly racemic endo-2a was obtained (Table 1, entry 1). However, in the case of $\left(S_{a}, R, R\right)-9$ $\mathrm{Cu}(\mathrm{OTf})_{2}, 88 / 11 d r$ and excellent enantioselection $>99: 1$ was obtained for the exo-diastereoisomer 2a (Table 1, entry $2)$. When using the enantiomeric ligand $\left(R_{a}, S, S\right)-9$ the corresponding enantiomer exo-2a was mainly isolated (Table 1, entry 3). By contrast, complex formed by phosphoramidite $\left(S_{a}, S, S\right)-9$ and $\mathrm{Cu}(\mathrm{OTf})_{2}$ demonstrated to be a mismatched combination because the reaction gave the oposite diastereoselection with nule enantioselection (Table 1 , entry 4). $\mathrm{Cu}(\mathrm{OTf})_{2}$ was the most appropriate copper(II) salt rather than $\mathrm{Cu}(\mathrm{OAc})_{2}$ in terms of both diastereo- and enantioselection (Table 1, compare entries 2 and 5). Copper(I) bromide did not afford the expected results, whilst $\mathrm{Cu}(\mathrm{OTf}) \cdot \mathrm{C}_{6} \mathrm{H}_{6}$ showed the same result that the obtained in the reaction run with $\mathrm{Cu}(\mathrm{OTf})_{2}$ (Table 1, entries 6 and 7). We selected the catalyst formed by $\mathrm{Cu}(\mathrm{OTf})_{2}$ because reactions involving copper(I) usually require inert atmosphere and degassed solvents in order to avoid dismutation. The presence of an external base is crucial for the reaction success, triethylamine being more adequate than DIPEA, and DABCO (Table 1, compare entry 2 with entries 8-10). The solvent effect was also dramatic because almost racemic mixtures of the product 2a were isolated when $\mathrm{Et}_{2} \mathrm{O}$, THF, MeCN or DCM were employed, although in the last example the diastereomeric exo/endo ratio was the highest achieved in this transformation and in very good yields (Table 1, entries 11-14). Unexpectely, in all the cases, cycloadduct endo-2a was obtained in racemic form.

Smaller amounts of a catalyst loading $(3 \mathrm{~mol} \%)$ in the reaction gave lower yield $(55 \%)$ and similar enantioselectivity of 2a (not included in Table 1). The absolute configuration of exo-cycloadduct $\mathbf{2 a}$ was established according to the retention times in HPLC using chiral columns and comparison with the data obtained for the same known product. ${ }^{4 c, 9}$

(15) Chiral phosphoramidite 9-CuOTf has been isolated and characterized (IR, ${ }^{1} \mathrm{H}$ NMR, ${ }^{13} \mathrm{C}$ NMR, ${ }^{31} \mathrm{P}$ NMR, ${ }^{19} \mathrm{~F}$ NMR, and HRMS) by Maksymowicz, R. M.; Roth, P. M. C.; Fletcher, S. P. Nature Chem. 2012, 4, 649. 
Table 1. Optimization of the 1,3-DC between 10a and 11a
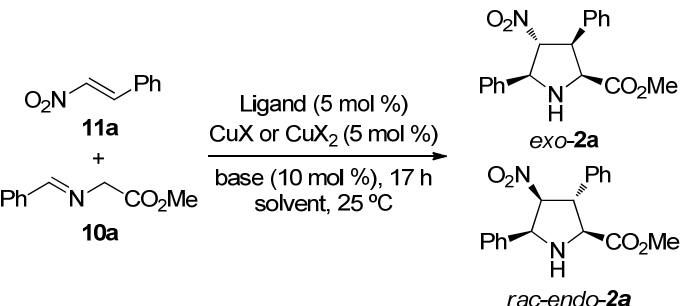

\begin{tabular}{|c|c|c|c|c|c|c|}
\hline & $\begin{array}{l}\text { copper } \\
\text { salt }\end{array}$ & $\begin{array}{l}\text { solvent/ } \\
\text { base }\end{array}$ & ligand & $\begin{array}{l}\text { yield } \\
(\%)^{a}\end{array}$ & $d r^{\mathrm{b}}$ & $e r_{\text {exo }}{ }^{\mathrm{c}}$ \\
\hline 1 & $\mathrm{Cu}(\mathrm{OTf})_{2}$ & $\mathrm{PhMe} / \mathrm{Et}_{3} \mathrm{~N}$ & $\left(S_{a}\right)-\mathbf{8}$ & 78 & $24 / 76$ & $50: 50$ \\
\hline 2 & $\mathrm{Cu}(\mathrm{OTf})_{2}$ & $\mathrm{PhMe} / \mathrm{Et}_{3} \mathrm{~N}$ & $\left(S_{\mathrm{a}}, R, R\right)-\mathbf{9}$ & 79 & $89 / 11$ & $>99: 1$ \\
\hline 3 & $\mathrm{Cu}(\mathrm{OTf})_{2}$ & $\mathrm{PhMe} / \mathrm{Et}_{3} \mathrm{~N}$ & $\left(R_{\mathrm{a}}, S, S\right)-\mathbf{9}$ & 79 & $89 / 11$ & $<1: 99$ \\
\hline 4 & $\mathrm{Cu}(\mathrm{OTf})_{2}$ & $\mathrm{PhMe} / \mathrm{Et}_{3} \mathrm{~N}$ & $\left(S_{\mathrm{a}}, S, S\right)-\mathbf{9}$ & 16 & $20 / 80$ & $50: 50$ \\
\hline 5 & $\mathrm{Cu}(\mathrm{OAc})_{2}$ & $\mathrm{PhMe} / \mathrm{Et}_{3} \mathrm{~N}$ & $\left(S_{\mathrm{a}}, R, R\right)-\mathbf{9}$ & 41 & $68 / 32$ & $94: 6$ \\
\hline 6 & $\mathrm{CuBr}$ & $\mathrm{PhMe} / \mathrm{Et}_{3} \mathrm{~N}$ & $\left(S_{\mathrm{a}}, R, R\right)-\mathbf{9}$ & nd & nd & nd \\
\hline 7 & $\mathrm{Cu}(\mathrm{OTf})^{\mathrm{d}}$ & $\mathrm{PhMe} / \mathrm{Et}_{3} \mathrm{~N}$ & $\left(S_{\mathrm{a}}, R, R\right)-\mathbf{9}$ & 78 & $89 / 11$ & $>99: 1$ \\
\hline 8 & $\mathrm{Cu}(\mathrm{OTf})_{2}$ & $\mathrm{PhMe} /$ none & $\left(S_{\mathrm{a}}, R, R\right)-\mathbf{9}$ & 16 & $20 / 80$ & $50: 50$ \\
\hline 9 & $\mathrm{Cu}(\mathrm{OTf})_{2}{ }^{\mathrm{e}}$ & PhMe/DIPEA & $\left(S_{\mathrm{a}}, R, R\right)-\mathbf{9}$ & 13 & $66 / 34$ & $70: 30$ \\
\hline 10 & $\mathrm{Cu}(\mathrm{OTf})_{2}{ }^{\mathrm{f}}$ & $\mathrm{PhMe} / \mathrm{DABCO}$ & $\left(S_{\mathrm{a}}, R, R\right)-\mathbf{9}$ & 79 & $84 / 16$ & $50: 50$ \\
\hline 11 & $\mathrm{Cu}(\mathrm{OTf})_{2}{ }^{\mathrm{g}}$ & $\mathrm{Et}_{2} \mathrm{O} / \mathrm{Et}_{3} \mathrm{~N}$ & $\left(S_{\mathrm{a}}, R, R\right)-\mathbf{9}$ & 50 & $78 / 22$ & $58: 42$ \\
\hline 12 & $\mathrm{Cu}(\mathrm{OTf})_{2}{ }^{\mathrm{h}}$ & $\mathrm{THF} / \mathrm{Et}_{3} \mathrm{~N}$ & $\left(S_{\mathrm{a}}, R, R\right)-\mathbf{9}$ & 70 & $84 / 16$ & $55: 45$ \\
\hline 13 & $\mathrm{Cu}(\mathrm{OTf})_{2}{ }^{i}$ & $\mathrm{MeCN} / \mathrm{Et}_{3} \mathrm{~N}$ & $\left(S_{\mathrm{a}}, R, R\right)-\mathbf{9}$ & 40 & $64 / 36$ & $55: 45$ \\
\hline 14 & $\mathrm{Cu}(\mathrm{OTf})_{2}{ }^{\mathrm{j}}$ & $\mathrm{DCM} / \mathrm{Et}_{3} \mathrm{~N}$ & $\left(S_{\mathrm{a}}, R, R\right)-\mathbf{9}$ & 82 & $93 / 4$ & $50: 50$ \\
\hline
\end{tabular}

a Isolated yield of the exo-cycloadduct after flash chromatography. ${ }^{\mathrm{b}}$ exo/endo ratio from the crude product, determined by ${ }^{1} \mathrm{H}$ NMR. Other stereoisomers were detected in low proportions. ${ }^{\mathrm{c}}$ For the major stereoisomer. ${ }^{\mathrm{d}}$ Benzene complex.

The reaction of nitrostyrene 11a and imino ester 10a was studied at lower temperatures. At $-80{ }^{\circ} \mathrm{C}$ a $1: 1$ mixture of the corresponding exo-cycloadduct-2a and the syn-imino ester 12a was obtained. After acidic treatment at $-80{ }^{\circ} \mathrm{C}$ and simple extractive work-up, the corresponding syn-amino ester 13a and as exo-2a hydrochloride were isolated (Scheme 1). Diastereomeric ratios of 13a and enantiomeric ratios of both exo/endo-2a and syn-13a were independent of the working temperature. ${ }^{16}$

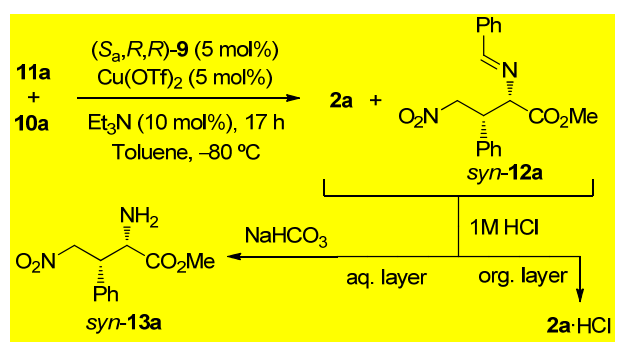

Scheme 1. Reaction at low temperature.

The scope of the reaction was surveyed by modifying the structure of the 1,3-dipole precursor and then varying the nitroalkene aromatic substituent (Table 2). The presence of an isopropyl group in the ester moiety improved the exo/endo ratio of the result obtained for the methyl ester

(16) See, supporting information for more details. derivative keeping the same enantioselection, but the reaction of the isopropyl ester afforded larger amounts of other steresoisomers (ca. 20\%) (Table 2, entries 1 and 2). When $\alpha$-substituted amino acids, such as leucine, and phenylalanine, were employed in the elaboration of imino esters $\mathbf{1 0}$ moderate yields of enantiomerically enriched exocycloadducts 2c-2d were isolated (Table 2, entries 3, and 4). The stereochemical course or the reaction was also influenced by the aryl substituent of the imino ester (Table 2 , entries 5-10). Thus, a methyl group bonded at the $O$ position decreased both, the diastereo- and enantiomeric ratios in $2 \mathbf{e}$ (Table 2 , entry 5 ). The $m$ - and $p$-substitution increased these two parameters up to 89/11 exo/endo ratio with higher enantioselections $90: 10$ and $94: 6$ er for compounds $2 \mathbf{f}$ and $\mathbf{2 g}$, respectively (Table 2, entries 6 and 7). Other $p$-halogen-substituted imino esters gave very good results, especially the fluoroaryl derivative $\mathbf{2} \mathbf{i}$, which was obtained with a 99:1 er (Table 2, entries 8 and 9). The 2naphthyl derivative also gave a similar diastereoselection $(86 / 14)$ although the er of product $\mathbf{2 j}$ was sensibly lower (85:15) (Table 2, entry 10).

Several $\beta$-arylnitroalkenes were allowed to undergo this 1,3-DC employing imino ester 10a (Table 2, entries 11-17). The $O$-substituted aryl group afforded very good enantioselection with lower endo/exo ratio in $\mathbf{2 k}$ than the corresponding $m$ - and $p$-substituted alkenes as, for example, $2 \mathbf{l}$ and $\mathbf{2 m}$ (Table 2, entries 11-13). Again, the $p$-substitution (Table 2, entries 13-17) resulted to be most favorable for this transformation such as it was exemplified by molecules 20 and 2p (Table 2, entries 15 and 16). Again, the presence of the isopropyl ester afforded the same results obtained when methyl ester was used (Table 2, compare entries 13 and 14). The same enantioselection was achieved with both esters but better diastereoselection was got using the methyl substituent. Heteroaryl substituents anchored to the imino ester did not afford any profitable result except the 2-furyl substituent in the dipolarophile skeleton generated product $2 \mathbf{r}$ in moderate yield, and good diastereo- and enantiomeric ratio (Table 2 , entry 18 ). The reaction performed with an aliphatic nitroalkene $\left(\mathrm{R}^{4}=\right.$ cyclohexyl) the corresponding endo-2 derivative was obtained as a racemic mixure in moderate yield and impurified with other diastereoisomers (not included in Table 2).

Table 2 also shows chemical yields and enantiomeric ratios of recrystallized solid compounds previously purified by flash chromatography. In all these examples the diastereoselectivity was excellent affording exclusively the exo-derivative 2 . The enantiomeric ratio was notably increased after recrystallization of purified adducts 2 obtaning almost enantiopure samples (Table 2, entries 7-13, 15 and 16-17). An exception was the example performed with $o$-methyl substituted imino ester 10 whose er could not be improved (Table 2, entry 5).

In our hands, $\left(S_{a}, R, R\right)-9-\mathrm{Cu}(\mathrm{OTf})_{2}$ complex could not be successfully recrystallized. However, ${ }^{31} \mathrm{P}$ NMR spectra revealed a signal at $57.14 \mathrm{ppm}$ and a monomeric structure can be postulated as catalytic species according to electrospray ionization-MS $\left(\mathrm{M}^{+}, 602\right)^{16}$ and the lack of nonlinear effects (NLE). ${ }^{14}$ 
DFT calculations on the $\left(S_{a}, R, R\right)-\mathbf{9} \cdot \mathrm{Cu}(\mathrm{OTf})_{2}$ catalyzed reaction to obtain $2 \mathrm{a}$, showed that the coordination sphere of $\mathrm{Cu}$ (II) atom is saturated by a OTf moiety. The most stable transition structures located are depicted in Figure 3. $(S, S)$ exo-TS1-2a was found to be about $1.5 \mathrm{kcal} \mathrm{mol}^{-1}$ more stable than its enantiomeric counterpart. These calculations support a computed $e r_{\text {exo }}$ of about $92 \%$, in good agreement with the experimental results.

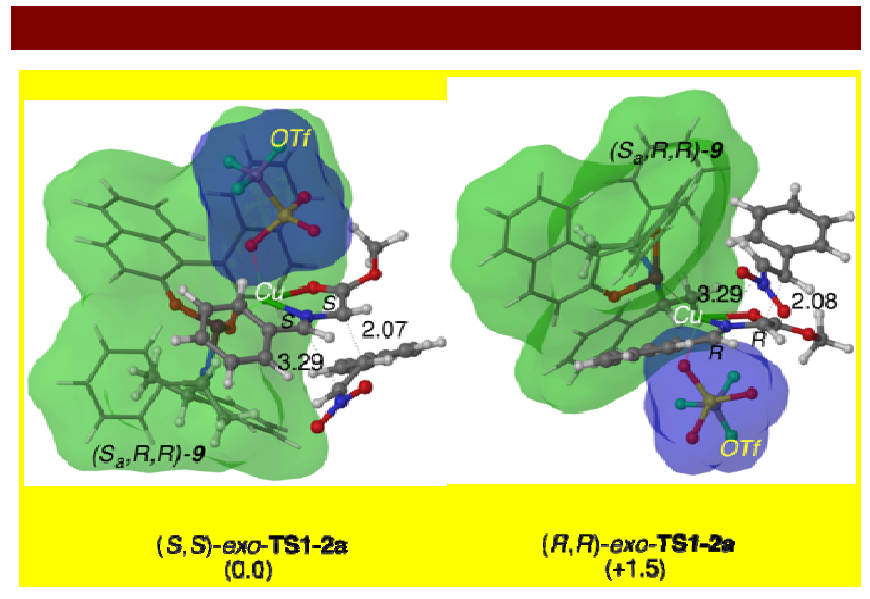

Figure 3. Main geometric features and relative energies (in kcal $\mathrm{mol}^{-1}$ ) of the computed transition structures associated with the first step of the reaction between 11a and $\left(S_{\mathrm{a}}, R, R\right)-\mathbf{9} \cdot \mathrm{CuOTf}-\mathrm{II}$ with 10a computed at M06/LANL2DZ//ONIOM (B3LYP/LANL2DZ:UFF) $+\triangle$ ZPCE level of theory. Bond-lengths are given in $\AA$. The chiral ligand and OTf moiety are highligted in green and blue, respectively.

In summary, we can conclude that chiral phosphoramidites can be used as very good privileged ligands in the copper(II)-catalyzed 1,3-DC of azomethine ylides with $\beta$-nitrostyrenes at room temperature. In general, aromatic substituents in both components of the reaction are suitable. These simple reaction conditions allow the preparation of a variety of prolines 2 ; useful candidates for organocatalyzed asymmetric aldol reactions. ${ }^{3}$ A notable increment of the enantiomeric ratio occurred by recrystallization of the purified exo-products. The isolation of Michael-type addition compounds at lower temperatures supported the existence of a stepwise mechanism. The experimentally obtained diastereo- and enantioselectivities were supported by DFT calculations.

Acknowledgments. This work has been supported by the Spanish Ministerio de Economía y Competitividad (MINECO) (Consolider INGENIO 2010 CSD2007-00006, CTQ2010-20387), FEDER, Generalitat Valenciana (PROMETEO/2009/039), and by the University of Alicante. L. M. C. thanks the MINECO for a FPI fellowship. The DIPC and the SGI/IZO-SGIker UPV/EHU (European Social Fund) are gratefully acknowledged for generous allocation of computational resources.

Supporting Information Available. Experimental procedures, full spectroscopic data for all new compounds an computadional data are available free of charge via the Internet at http://pubs.acs.org. 
Table 2. Scope of the 1,3-DC between iminoesters and nitroalkenes catalyzed by $\left(S_{\mathrm{a}}, R, R\right)-\mathbf{9} \cdot \mathrm{Cu}(\mathrm{OTf})_{2}$ complex.
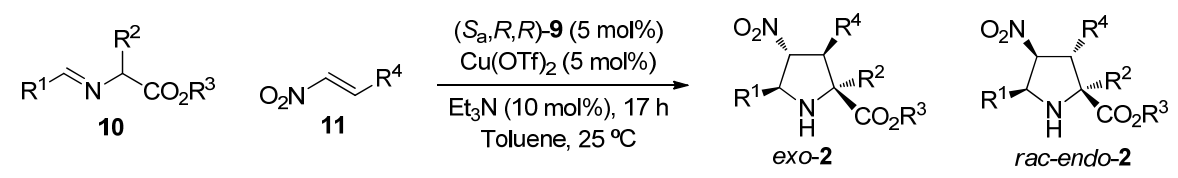

\begin{tabular}{|c|c|c|c|c|c|c|c|c|c|c|}
\hline entry & $\mathrm{R}^{1}$ & $\mathrm{R}^{2}$ & $\mathrm{R}^{3}$ & $\mathrm{R}^{4}$ & 2 & yield $(\%)^{\mathrm{a}}$ & exo/endo ${ }^{\mathrm{b}}$ & $e r_{e x o}$ & yield $(\%)^{\mathrm{c}}$ & $e r_{\text {exo }}^{\mathrm{d}}$ \\
\hline 1 & $\mathrm{Ph}$ & $\mathrm{H}$ & $\mathrm{Me}$ & $\mathrm{Ph}$ & $2 a$ & 79 & $89 / 11$ & $>99: 1$ & 68 & $>99: 1$ \\
\hline 2 & $\mathrm{Ph}$ & $\mathrm{H}$ & $\operatorname{Pr}^{\mathrm{i}}$ & $\mathrm{Ph}$ & $2 b$ & $69^{\mathrm{e}}$ & $99 / 1$ & $>99: 1$ & 60 & $>99: 1$ \\
\hline 3 & $\mathrm{Ph}$ & $\mathrm{Bu}^{\mathrm{i}}$ & $\mathrm{Me}$ & $\mathrm{Ph}$ & $2 c$ & 60 & $92 / 8$ & $>99: 1$ & 47 & $>99: 1$ \\
\hline 4 & $\mathrm{Ph}$ & $\mathrm{PhCH}_{2}$ & $\mathrm{Me}$ & $\mathrm{Ph}$ & $2 d$ & 65 & $75 / 25$ & $>99: 1$ & 51 & $>99: 1$ \\
\hline 5 & $2-\mathrm{MeC}_{6} \mathrm{H}_{4}$ & $\mathrm{H}$ & $\mathrm{Me}$ & $\mathrm{Ph}$ & $2 \mathbf{e}$ & 51 & $59 / 41$ & $75: 25$ & 37 & $77: 23$ \\
\hline 6 & $3-\mathrm{MeC}_{6} \mathrm{H}_{4}$ & $\mathrm{H}$ & $\mathrm{Me}$ & $\mathrm{Ph}$ & $2 f$ & 61 & $79 / 21$ & $90: 10$ & $-{ }^{f}$ & $-{ }^{f}$ \\
\hline 7 & $4-\mathrm{MeC}_{6} \mathrm{H}_{4}$ & $\mathrm{H}$ & $\mathrm{Me}$ & $\mathrm{Ph}$ & $2 g$ & 59 & $79 / 21$ & $94: 6$ & 46 & $99: 1$ \\
\hline 8 & 4- $\mathrm{BrC}_{6} \mathrm{H}_{4}$ & $\mathrm{H}$ & $\mathrm{Me}$ & $\mathrm{Ph}$ & $2 \mathrm{~h}$ & 76 & $89 / 11$ & $95: 5$ & 69 & $99: 1$ \\
\hline 9 & 4- $-\mathrm{FC}_{6} \mathrm{H}_{4}$ & $\mathrm{H}$ & $\mathrm{Me}$ & $\mathrm{Ph}$ & $2 \mathbf{i}$ & 70 & $87 / 13$ & $99: 1$ & 62 & $>99: 1$ \\
\hline 10 & 2-Naphthyl & $\mathrm{H}$ & $\mathrm{Me}$ & $\mathrm{Ph}$ & $2 \mathbf{j}$ & 70 & $86 / 14$ & $85: 15$ & 59 & $94: 6$ \\
\hline 11 & $\mathrm{Ph}$ & $\mathrm{H}$ & $\mathrm{Me}$ & 2- $\mathrm{BrC}_{6} \mathrm{H}_{4}$ & $2 \mathbf{k}$ & 56 & $73 / 27$ & $96: 4$ & 48 & $98: 2$ \\
\hline 12 & $\mathrm{Ph}$ & $\mathrm{H}$ & $\mathrm{Me}$ & $3-\mathrm{BrC}_{6} \mathrm{H}_{4}$ & 21 & 61 & $90 / 10$ & $94: 6$ & 52 & $98: 2$ \\
\hline 13 & $\mathrm{Ph}$ & $\mathrm{H}$ & $\mathrm{Me}$ & 4- $\mathrm{BrC}_{6} \mathrm{H}_{4}$ & $2 m$ & 70 & $86 / 14$ & $95: 5$ & 64 & $99: 1$ \\
\hline 14 & $\mathrm{Ph}$ & $\mathrm{H}$ & $\operatorname{Pr}^{\mathrm{i}}$ & 4- $\mathrm{BrC}_{6} \mathrm{H}_{4}$ & $2 n$ & 72 & $80 / 20$ & $95: 5$ & $-{ }^{f}$ & $-{ }^{f}$ \\
\hline 15 & $\mathrm{Ph}$ & $\mathrm{H}$ & $\mathrm{Me}$ & $4-\mathrm{MeC}_{6} \mathrm{H}_{4}$ & 20 & 48 & $82 / 18$ & $99: 1$ & 40 & $99: 1$ \\
\hline 16 & $\mathrm{Ph}$ & $\mathrm{H}$ & $\mathrm{Me}$ & 4- $(\mathrm{MeO}) \mathrm{C}_{6} \mathrm{H}_{4}$ & $2 p$ & 68 & $72 / 28$ & $98: 2$ & 63 & $99: 1$ \\
\hline 17 & $\mathrm{Ph}$ & $\mathrm{H}$ & $\mathrm{Me}$ & $4-\mathrm{FC}_{6} \mathrm{H}_{4}$ & $2 q$ & 73 & $82 / 12$ & $96: 4$ & 70 & $99: 1$ \\
\hline 18 & $\mathrm{Ph}$ & $\mathrm{H}$ & $\mathrm{Me}$ & 2-Furyl & $2 r$ & 41 & $77 / 23$ & $91: 9$ & $-{ }^{f}$ & $-^{f}$ \\
\hline
\end{tabular}

${ }^{a}$ Isolated yield of the major cycloadduct after flash chromatography $\left(\mathrm{SiO}_{2}\right) .{ }^{\mathrm{b}}$ From the crude product, determined by ${ }^{1} \mathrm{H}$ NMR. Other stereoisomers were detected in low proportions. ${ }^{\mathrm{c}}$ Isolated yield after recrystallization for the exo-adduct based on the starting compound $\mathbf{1 0}{ }^{\mathrm{d}}$ After recrystallization. e $20 \%$ of the other stereoisomers were also obtained. ${ }^{\mathrm{f}}$ Oily products. 